\title{
Calibration and Validation of Decision Support System for Agro-Technology Transfer Model for Simulating Growth and Yield of Maize in Bangladesh
}

\author{
F. Ahmed ${ }^{1}$, Apurba K. Choudhury ${ }^{1}$, S. Akhter ${ }^{1}$, M. A. Aziz ${ }^{1}$, Jatish C. Biswas ${ }^{2}$, M. Maniruzzaman ${ }^{2}$, \\ M. Main Uddin Miah', M. M. Rahman', M. A. H. S. Jahan', Imrul Mosaddek Ahmed1, R. Sen', \\ S. Ishtiaque ${ }^{1}$, A. F. M. Tariqul Islam¹, M. M. Haque², M. Belal Hossain'², Naveen Kalra4, \\ M. Hafijur Rahman'
}

\author{
${ }^{1}$ Bangladesh Agricultural Research Institute, Gazipur, Bangladesh \\ ${ }^{2}$ Bangladesh Rice Research Institute, Gazipur, Bangladesh \\ ${ }^{3}$ Bangabandhu Sheikh Mujibur Rahman Agricultural University, Gazipur, Bangladesh \\ ${ }^{4}$ Consultant CRP-II Project, KGF, Dhaka, Bangladesh \\ Email: `faruquebari@gmail.com, bd_apurba@yahoo.com, sohela_akhter@yahoo.com, jatishb@yahoo.com, \\ mzamaniwm@yahoo.com,mmumiahbsmrau@gmail.com, mizan@bsmrau.edu.bd, belal.bari@gmail.com, \\ kbdimrul@yahoo.com, senranjitbd@yahoo.com, ishtiaque@bari.gov.bd, afmtareq@gmail.com,mhaquesoil@yahoo.com, \\ belal.iwm@gmail.com,drnkalra@gmail.com,m58abdulaziz@yahoo.com
}

How to cite this paper: Ahmed, F., Choudhury, A.K., Akhter, S., Aziz, M.A., Biswas, J.C., Maniruzzaman, M., Miah, M.M.U., Rahman, M.M., Jahan, M.A.H.S., Ahmed, I.M., Sen, R., Ishtiaque, S., Islam, A.F.M.T., Haque, M.M., Hossain, M.B., Kalra, N. and Rahman, M.H. (2017) Calibration and Validation of Decision Support System for Agro-Technology Transfer Model for Simulating Growth and Yield of Maize in Bangladesh. American Journal of Plant Sciences, 8, 1632-1645.

https://doi.org/10.4236/ajps.2017.87113

Received: April 16, 2017

Accepted: June 19, 2017

Published: June 23, 2017

Copyright $\odot 2017$ by authors and Scientific Research Publishing Inc. This work is licensed under the Creative Commons Attribution International License (CC BY 4.0).

http://creativecommons.org/licenses/by/4.0/

\begin{abstract}
Maize is an emerging important crop in Bangladesh because of its high yield potential and economic profitability compared to rice and wheat crops. There is a need to understand the growth and yield behavior of this crop in varying production environments of Bangladesh. Crop model such as Decision Support System For Agro-technology Transfer (DSSAT) version 4.6 (DSSAT hereafter) can be utilized cost effectively to study the performances of maize under different production environments. It needs to calibrate and validate DSSAT model for commonly cultivated maize cultivars in Bangladesh and subsequently take the model to various applications, including inputs and agronomic management options and climate change that impacts analyses. So, the present study was undertaken to firstly calibrate DSSAT model for popular four hybrid maize cultivars (BARI Hybrid Maize-7, BARI Hybrid Maize-9, Pioneer 30B07 and NK-40). Subsequently, it proceeded with the validation with independent field data sets for evaluating their growth performances. The genetic coefficients for these cultivars were evaluated by using Genotype coefficient calculator (GENCALC) and Generalized likelihood uncertainty estimation (GLUE) module of DSSAT on the basis of first season experiment. The performance of the model was satisfactory and within the significant limits. After calibration, the model was tested for its performance through valida-
\end{abstract}


tion procedure by using second season data. The model performed satisfactorily through phenology, biomass, leaf area index (LAI) and grain yield. Phenology, as estimated through days to flower initiation and maturity, was in good agreement, although simulated results were slightly over predicted compared to observed values but within the statistical significance limit $(<\mathrm{p}$ value $=0.05)$. The periodic LAI and biomass were simulated satisfactorily when compared with observed values at specific growth stages of the crop. The final yield values (10.12 to $10.59 \mathrm{t} \cdot \mathrm{ha}^{-1}$ ) were in close agreement with the observed values (10.16 to $10.94 \mathrm{t} \cdot \mathrm{ha}^{-1}$ ), as the percentage error was within tolerable limit $(0.39 \%$ to $6.81 \%)$. The model has been successfully calibrated and validated for Gazipur environment and now can be used for climate change impact studies for similar environments in Bangladesh.

\section{Keywords}

Calibration, Validation, DSSAT Model and Maize

\section{Introduction}

Maize is one of the most important cereal crops in Bangladesh. Its production area is increasing day by day due to its versatile use and high yield potential. Maize is mainly used as poultry and dairy feed in Bangladesh. It can be grown in rabi (winter) as well as kharif (monsoon) seasons. In rabi season, clear sky and low temperature lengthen its vegetative growth, which is required for higher yield, whereas in kharif maize, high temperature shortens its vegetative growth stage and results in lower grain yield. Increase in temperature, as predicted through different models, the crop sector in Bangladesh will suffer more from climate change impacts.

To predict future climate change impact on maize productivity, crop simulation model can be effectively used. Crop models are being used to evaluate the impact of climate change on crop production as a result of increased greenhouse gases [1] [2]. Crop models have also been used in inputs and resource management options for sustained agricultural production [3] [4]. The usefulness of the models has generated a series of programs able to simulate crop development and production by using genotypic, environmental, and management information [5] [6]. One of these support tools DSSAT that has been developed and used for more than 15 years by researchers associated with agriculture in approximately 100 countries around the world [7]. The DSSAT model consists of a set of independent programs that operate simultaneously on simulation models using information from the soil, climate, crop, and agronomic management databases [8] [9].

With the development of tactical or strategic decisions for improving agricultural productivity in Bangladesh under climate change situations, a new approach like crop models could be used. To date, there have been some efforts in evaluating or adapting some dynamic crop models in Bangladesh. However, the 
progress has been very slow. Since most models have been developed elsewhere in Europe and USA, their use outside their domain of development requires a great deal of data for their calibration and validation, which is not readily available or difficult to obtain. The most important aspects in evaluating crop models include determination of cultivar specific parameters or coefficients [10]. Cultivar coefficients for maize varieties in Bangladesh are not known and the common varieties used in this region are not included in the cultivar database of DSSAT [11]. There is a strong need to use this model with maize as a test crop in this region.

Accurate estimation of crop cultivar coefficients is the entry point into dynamic crop model for its use in research as well as decision making and improvement for identification and consequently narrowing gaps in our knowledge over crops and biophysical aspects for improved agricultural productivity. Calibrated crop models with cultivar parameters can be used to optimize crop management [12] to evaluate the impacts of climate change [9], to develop options and to optimize resource use [13] or to develop new crop genotypes [14].

Keeping these imperatives in view, the present study was undertaken to evaluate the coefficients of four maize cultivars adapted in Bangladesh. Specific objectives were to determine maize crop growth and development indices under optimum growing conditions, to compute maize cultivars coefficients and calibrate DSSAT model for assessing growth and yield of maize under various biotic and abiotic stresses.

\section{Materials and Methods}

\subsection{Field Experiments}

\section{Site description}

The station is located at $23.45^{\circ} \mathrm{N}$ and $90.23^{\circ} \mathrm{E}$ and $8 \mathrm{~m}$ above mean sea level. The study area experiences a sub-tropical monsoon climate. Seventy percent of the total rainfall is received during July to September, with average annual rainfall of $2148 \mathrm{~mm}$. April is the hottest month, with average minimum and maximum temperatures of $23.6^{\circ} \mathrm{C}$ and $33.7^{\circ} \mathrm{C}$, respectively. The coldest month is December where the average minimum and maximum temperatures are $14.1^{\circ} \mathrm{C}$ and $26.4^{\circ} \mathrm{C}$, respectively. Average sunshine hours are $6.52 \mathrm{hr} \cdot \mathrm{day}^{-1}$. The soils of the study site were characterized as silt clay loam with moderate drainage.

\subsection{DSSAT (CERES-Maize) Model}

DSSAT was developed by an international network of scientists, cooperating in the International Benchmark Sites Network for Agrotechnology Transfer project (IBSNAT Project). DSSAT version 4.6 was utilized for the study. The DSSAT simulate crop growth, development and yield using a defined data set on crop management, minimum weather data and soil profile parameters. Some of the crop management data required to simulate DSSAT include crop, cultivar, planting date, row and plant spacing, fertilizer-N levels, tillage practices and organic amendments [7]. Also data inputs include physiological stages of crop 
growth such as anthesis dates and days to maturity. Minimum weather data sets consist of maximum and minimum temperatures, solar radiation and rainfall. If sunshine hours data is available, then Weatherman module in DSSAT coverts it into solar radiation. Soil profile parameters include depth of soil, soil physical and chemical characters.

Weather data were collected from the weather station located at BRRI Gazipur, which is very near to experimental site. Initial soil profile for the experimental site was collected for physical and chemical characteristics. The data on soil characteristics such as soil moisture, $\mathrm{pH}$, bulk density, soil organic carbon and total-nitrogen were measured and stored in the soil input file (Table 5). The soil of the experiment was specified as silty clay loam. The crop management data were recorded throughout the growing seasons. The input files, such as weather file, soil file, experimental file and A \& T files (average measured data file, annual as well as temporal), were prepared to calibrate and validate the Crop Environment Resource Synthesis (CERES)-Maize model. The first year experiment was used for calibration of the model for test cultivars and the second year experiment was used for validation purpose.

CERES-Maize model is a predictive and deterministic model designed to simulate maize growth, soil, water and temperature and soil nitrogen dynamics at a field scale for one growing season. The CERES-Maize model in DSSAT requires a set of six cultivar specific parameter for its calibration (Table 1). Four of them (P1, P2, P5, and PHINT) control the timing of phenological stages, and the remaining two (G2 and G3) characterize the potential yield under optimal conditions. By running of GLUE model, and simultaneous carrying out sensitivity analyses with these coefficients, the coefficients for the tested cultivars were computed, through process of calibration.

\subsection{Field Experiments for Model Calibration and Validation}

Two field experiments were carried out at the research field of Plant Physiology Division, BARI, Gazipur during rabi seasons of 2014-15 and 2015-16. The crops were grown under no stress condition. First year's data were s used to calibrate genetic coefficients and second year's data were used for the validation of model.

Table 1. Maize Cultivar Coefficients for running of DSSAT.

\begin{tabular}{|c|c|c|}
\hline Coefficient & Unit & Definition \\
\hline P1 & ${ }^{\circ} \mathrm{C}$ day & Thermal time from seedling emergence to the end of the juvenile phase \\
\hline P2 & Days & $\begin{array}{l}\text { Extent to which development is delayed for each hour increase in } \\
\text { photoperiod above the longest photoperiod at which development } \\
\text { proceeds at a maximum rate (which is considered to be } 12.5 \mathrm{~h} \text { ). }\end{array}$ \\
\hline P5 & ${ }^{\circ} \mathrm{C}$ day & Thermal time from silking to physiological maturity \\
\hline G2 & Number & Maximum possible number of kernels per plant. \\
\hline G3 & mg day ${ }^{-1}$ & $\begin{array}{l}\text { Kernel filling rate during the linear grain filling } \\
\text { stage under optimum conditions }\end{array}$ \\
\hline PHINT & ${ }^{\circ} \mathrm{C}$ day & $\begin{array}{l}\text { Phyllochron interval, the interval in thermal time } \\
\text { between successive leaf tip appearances }\end{array}$ \\
\hline
\end{tabular}


The site was previously fallow. Four adapted maize cultivars, BARI Hybrid Maize-7, BARI Hybrid Maize-9, NK-40 and Pioneer which are well adapted at farmer's level were used in this experiment, with yield potential ranging from 9.5to 10.0 t.ha ${ }^{-1}$. Seeds of BARI Hybrid Maize-7, and BARI Hybrid Maize-9 were collected from Bangladesh Agricultural Research Institute and others seeds were procured from market. Plant population for each cultivar was 83,333 plants ha ${ }^{-1}$ $(60 \mathrm{~cm} \times 20 \mathrm{~cm})$. Seed rate used in the study was $35 \mathrm{~kg} \cdot \mathrm{ha}^{-1}$. The unit plot size was $4.2 \mathrm{~m} \times 3 \mathrm{~m}$. Seeds were sown on November 18, 2014 with $60 \mathrm{~cm} \times 20 \mathrm{~cm}$ spacing, while sowing date in the second year was November 11, 2015. Fertilizers were applied at the rate of $250-55-100-30 \mathrm{~kg} \cdot \mathrm{ha}^{-1} \mathrm{~N}, \mathrm{P}, \mathrm{K}$ and $\mathrm{S}$ as urea, triple super phosphate (TSP), muriate of potash (MOP) and gypsum. One third of $\mathrm{N}$ and whole amount of TSP, MOP and gypsum were applied as basal at sowing. Remaining $2 / 3 \mathrm{~N}$ was top-dressed at 40 and 70 days after sowing (DAS). Irrigation was given as and when required to maintain adequate soil moisture available in the root zone. Standard agronomic practices were followed including weed and insects/pest control.

\subsection{Data Collection}

Soil characterization: Before conducting experiments, soil samples from 0 - 15, 15 - 30, 30 - 60, 60 - 90 and 90 - $120 \mathrm{~cm}$ depths were collected. The soil samples were analyzed for texture, bulk density, soil moisture, $\mathrm{pH}$, organic matter, total $\mathrm{N}$, field capacity, wilting point, bulk density, nitrate $\left(\mathrm{NO}_{3}{ }^{-}\right)$and ammonium $\left(\mathrm{NH}_{4}^{+}\right)$concentrations. Results of various physico-chemical properties of soil have been summarized in Table 2(a) and Table 2(b). Hydraulic conductivity, bulk density and saturated moisture content were derived from in-built pedotransfer functions module of SOIL of DSSAT.

Table 2. (a) Texture of the experimental soil; (b) physical and chemical properties of the experimental soil.

(a)

\begin{tabular}{cccc}
\hline Soil layer $(\mathrm{cm})$ & Sand (\%) & Silt (\%) & Clay (\%) \\
\hline $\mathbf{0}-\mathbf{1 5}$ & 15 & 45 & 40 \\
$\mathbf{1 5}-\mathbf{3 0}$ & 13 & 46 & 41 \\
$\mathbf{3 0}-\mathbf{6 0}$ & 19 & 42 & 39 \\
$\mathbf{6 0 - 9 0}$ & 24 & 39 & 37 \\
$\mathbf{9 0 - 1 2 0}$ & 21 & 41 & 38 \\
\hline
\end{tabular}

(b)

\begin{tabular}{cccccccc}
\hline $\begin{array}{c}\text { Soil layer } \\
(\mathrm{cm})\end{array}$ & $\mathrm{pH}$ & $\begin{array}{c}\text { Organic } \\
\text { carbon (\%) }\end{array}$ & $\begin{array}{c}\mathrm{Total} \mathrm{N} \\
(\%)\end{array}$ & $\begin{array}{c}\mathrm{NO}_{3}^{-} \mathrm{N} \\
(\mathrm{ppm})\end{array}$ & $\begin{array}{c}\mathrm{NH}_{4}^{+} \\
(\mathrm{ppm})\end{array}$ & $\begin{array}{c}\text { Field capacity } \\
\text { (fraction, vol.) }\end{array}$ & $\begin{array}{c}\text { Wilting point } \\
\text { (fraction, vol.) }\end{array}$ \\
\hline $\mathbf{0 - 1 5}$ & 6.4 & 0.9 & 0.093 & 13 & 2.0 & 0.42 & 0.19 \\
$\mathbf{1 5 - 3 0}$ & 6.3 & 0.72 & 0.07 & 10 & 2.0 & 0.45 & 0.2 \\
$\mathbf{3 0 - 6 0}$ & 6.2 & 0.53 & 0.055 & 8 & 3.0 & 0.41 & 0.21 \\
$\mathbf{6 0 - 9 0}$ & 6.2 & 0.32 & 0.035 & 6 & 3.5 & 0.4 & 0.2 \\
$\mathbf{9 0 - 1 2 0}$ & 6.1 & 0.24 & 0.027 & 4 & 3.7 & 0.42 & 0.22 \\
\hline
\end{tabular}




\subsection{Weather Information}

Daily weather data for both the growing seasons, including precipitation $(\mathrm{mm})$, minimum and maximum air temperatures $\left({ }^{\circ} \mathrm{C}\right)$, and sunshine hours were collated from the weather observatory. Solar radiation $\left(\mathrm{MJ} \cdot \mathrm{m}^{-2} \cdot \mathrm{d}^{-1}\right)$ was calculated from daily sunshine hours by using Weatherman of DSSAT. The weather files were created by using WEATHERMAN module of DSSAT for running of the model.

\subsection{Growth, Yield and Yield Attributes Recording}

Phenology: Every day we visited the crop field and recorded phonological information in terms of number of days required for attaining a particular growth stage. Ten plants from each plot were tagged at two-leaf stage which was used for destructive sampling to determine tassel initiation stage. Three randomly located plants of each cultivar from each replication were removed at regular intervals (every 2 - 3 day) starting from 12 days after emergence. The apex was dissected under a stereoscopic microscope and observed carefully. When the tip of tassel was visible under microscope data was recorded.

Fifty percentage tasseling date was recorded when tasseling was noticed in $50 \%$ of tagged plants. For observing physiological maturity we collected grains from different parts of the selected cobs like base, middle and tip when the cob became straw color at $2-3$ days interval. We recorded physiological maturity date when $50 \%$ of the grains showed black layer which indicate that no further accumulation of assimilates in grain is possible.

\subsection{Plant Growth Analysis}

Leaf area was measured by an automatic area meter (LI 3100 C, LI-COR, USA). For dry matter, leaves, stems and cobs were separated and dried in an oven at $80^{\circ} \mathrm{C}$ for 72 hours. Photosynthetically active radiation (PAR) was assumed as $50 \%$ of solar radiation, which were used for radiation use efficiency calculation.

\subsection{Yield, Yield Attributes and Biomass}

Grain yield and biomass at harvest were measured. As subsample, five plants were selected and the plant components were separated into stover husks and ears. The variables determined include the number of seeds per unit area (seed number $\cdot \mathrm{m}^{-2}$ ), seed weight $\left(\mathrm{dry} \cdot \mathrm{g} \cdot \mathrm{m}^{-2}\right)$, cob weight $\left(\mathrm{dry} \cdot \mathrm{g} \cdot \mathrm{m}^{-2}\right)$, and stover weight $\left(\right.$ dry.g. $\mathrm{m}^{-2}$ ). Maize was harvested at physiological maturity (BARI Hybrid Maize-7 and BARI Hybrid Maize-9 at 145 DAS, NK-40 at 146 DAS and Pioneer at 147 DAS). The yield components data were collected from 5 randomly selected plants prior to harvest from each plot. At-harvest, the yield data was recorded plot wise and analyzed statistically.

\subsection{Model Calibration}

The DSSAT crop models require genetic coefficients, which are specific for each cultivar to properly describe the processes related to growth, development and 
grain production. These coefficients allow the model to simulate performance of diverse genotypes under different soil, weather and management conditions [15]. The model was calibrated using field measured values of weather parameters, crop management and soil properties during 2014-2015 cropping season. Genetic coefficients were estimated by using observed anthesis and physiological maturity dates and grain yield of maize cultivars growing in 2014-15 and validation with data of 2015-2016 [16] [17].

Since none of the cultivars were previously introduced within DSSAT, we created them in the genetic file (MZCER046.CUL) of DSSAT-CSM. Initial values of the genetic coefficients were obtained from the medium maturity group cultivar DEKALB 591, already available in the DSSAT. The computed crop specific parameters (CSPs) values for DEKALB 591 cultivar were copied into MZCER046 CUL file to operate the simulation. An iterative approach was used to obtain reasonable genetic coefficients through trial and error adjustments until there was a match between the observed and simulated dates of anthesis and physiological maturity and grain yield [18] [19]. The derived genetic coefficients were used for model performance evaluation. In this study, water and nitrogen balance simulation controls were switched off, to ensure that no stress for water or nitrogen was experienced in the course of crop growth.

\subsection{Model Validation}

Model performance was evaluated by comparing the simulated versus observed values from the experiment of 2015-2016. Data for model validation include anthesis date, physiological maturity date, grain yield, potential grain weight and above ground biomass. Comparisons between measured and predicted maize yield and its attributes were carried out through percent error propagation.

\subsection{Statistical Analysis}

Statistical analysis, through coefficient of prediction $\left(\mathrm{R}^{2}\right)$, percent error and $p$ values was done in yield and its attributing characters were carried out to judge the performance of simulation compared to the observed values.

\section{Results and Discussion}

\subsection{Genetic Coefficients}

The genetic coefficients, as obtained through run of GLUE as part of Calibration exercise, are shown in Table 3. The genotypic coefficient $\mathrm{P} 1$ was $225^{\circ} \mathrm{C}$ day for BARI Hybrid Maize-7 and BARI Hybrid Maize-9, while that was $226^{\circ} \mathrm{C}$ day for PIONEER and NK-40. The P2 was same for all the varieties and P5 was $956^{\circ} \mathrm{C}$ day for BARI Hybrid Maize-7 and BARI Hybrid Maize-9, while that was 965 for PIONEER and 964 for NK-40. There was considerable variation among the cultivars in G2 and G3 but PHINT were the same amongst the cultivars. PHINT is critical in determining the duration of vegetative growth in maize, it is lower in temperate but higher in tropical climate. No cultivar specific parameters were found in literature for comparing the values we generated in our study. As culti- 
Table 3. Genetic coefficients of four maize cultivars

\begin{tabular}{ccccccc}
\hline Cultivar & $\begin{array}{c}\text { P1 } \\
\left({ }^{\circ} \mathrm{C} \text { day }\right)\end{array}$ & $\begin{array}{c}\text { P2 } \\
(\text { day })\end{array}$ & $\begin{array}{c}\text { P5 } \\
\left({ }^{\circ} \text { Cday }\right)\end{array}$ & $\begin{array}{c}\text { G2 } \\
\left(\# \text { grains ear }^{-1}\right)\end{array}$ & $\begin{array}{c}\text { G3 } \\
\left(\mathrm{mg} \mathrm{day}^{-1}\right)\end{array}$ & $\begin{array}{c}\text { PHINT } \\
\left({ }^{\circ} \text { C day }\right)\end{array}$ \\
\hline BARI Hybrid Maize-7 & 225 & 0.100 & 956 & 760 & 8.20 & 47 \\
BARI Hybrid Maize-9 & 225 & 0.100 & 956 & 765 & 8.40 & 47 \\
PIONEER & 226 & 0.100 & 965 & 768 & 8.50 & 47 \\
NK-40 & 226 & 0.100 & 964 & 765 & 8.50 & 47 \\
\hline
\end{tabular}

var specific parameters are not available in DSSAT model a same maturity cultivar was included in the DSSAT v4.5 cultivar database [11] for generation of genetic coefficient [20]. The generated cultivar specific parameters were within the range of DSSAT cultivar database. So, we can use the generated genetic coefficient in model application for Gazipur environment.

\subsection{Leaf Area Index (LAI)}

Figure 1 shows the performance evaluation of the model in terms of temporal course of leaf area index (LAI) during calibration process. Simulated LAI at different growth stages matched well with observed LAI although simulated LAI was slightly higher than the observed values. Per cent deviation was higher in the earlier stages of the crop growth, and subsequently the difference got narrowed down. The LAI was the highest at around 90 DAS thereafter it declined during 2014-15 season. A typical LAI pattern begins with a slow increase in the season, followed by a rapid increase of LAI until a maximum value is reached. LAI then declines as the leaves senesce and plants reaches physiologically maturity [21].

Figure 2 Shows simulated and observed LAI during 2015-2016 seasons as process for the model's validation, and performance seems to be satisfactory. In the beginning till anthesis, simulated values were slightly higher than the observed ones, but after anthesis the reverse trend was observed. However, the difference was marginal. Inter-varietal differences were not so significant throughout the growing periods. Figure 3 Shows relationship between simulated and observed maximum LAI value. The regression line was near to 1:1 line, indicating that the model was performing well under the test environment. The coefficient of determination $\left(R^{2}\right)$ was around $87 \%$ in case of trend line.

\subsection{Phenology, Yield and Biomass at Harvest}

Table 4 shows the observed and simulated values for days to anthesis, days to maturity, grain yield and tops weight at harvest. In 2014-15 seasons, days to anthesis for BARI Hybrid Maize-7 and BARI Hybrid Maize-9 were 81 days, while that was 82 days for PIONEER and NK-40 and simulated values were 80 days for all the four cultivars, with error percentage of 1.23 to $2.44 \%$. However, during 2015-2016 seasons, error percentage was a little bit higher, which ranged from $3.75 \%$ to $4.94 \%$. 


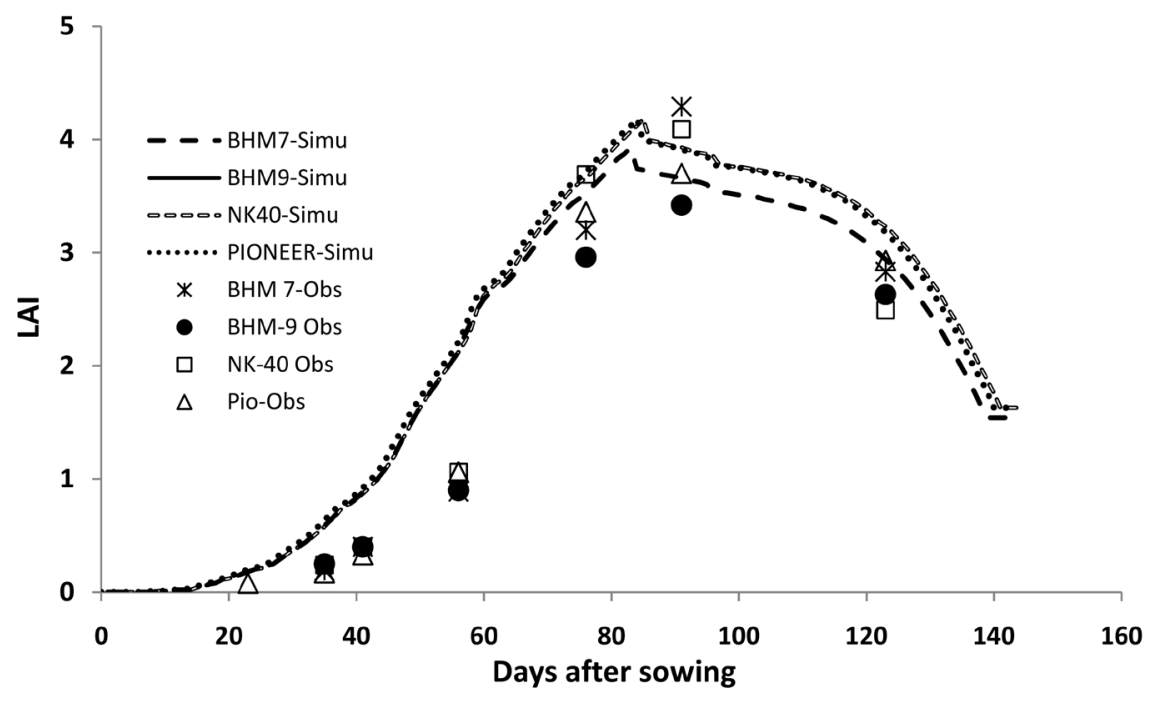

Figure 1. Simulated and observed LAI at different growth stages of maize cultivars during calibration process (2014-2015), BHM7 = BARI Hybrid Maize-7, BHM9 = BARI Hybrid Maize-9, Simu $=$ Simulated, Obs $=$ Observed (\% error range 4.2 to 11.2).

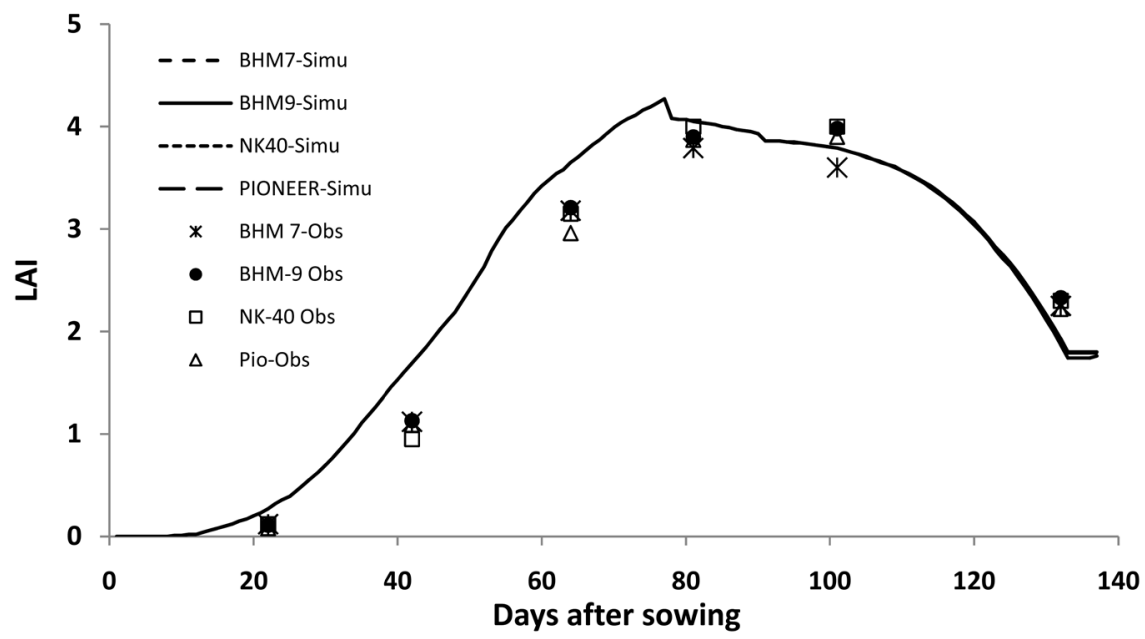

Figure 2. Simulated and observed leaf area index (LAI) at different growth stages of maize varieties during 2015-2016 (process of validation) BHM7 = BARI Hybrid Maize-7, BHM9 = BARI Hybrid Maize-9, Simu = Simulated, Obs = Observed. (\% error range 3.5 to 10.1).

Table 4. Simulated and observed values for four maize cultivars for days to anthesis, days to maturity, grain yield and biomass at.harvest (2014-2015, process of calibration).

\begin{tabular}{ccccccccccccccc}
\hline \multirow{2}{*}{ Cultivar } & \multicolumn{3}{c}{ Days to anthesis } & \multicolumn{3}{c}{ Days to maturity } & \multicolumn{3}{c}{ Grain yield $\left(\mathrm{t} \cdot \mathrm{ha}^{-1}\right)$} & \multicolumn{3}{c}{ Tops weight $\left(\mathrm{t} \cdot \mathrm{ha}^{-1}\right)$} \\
\cline { 2 - 11 } & \multicolumn{3}{c}{ Obs } & Sim. \%Error & Obs & Sim & \%Error & Obs. & Sim. & \%Error & Obs. & Sim. & \%Error \\
\hline BHM-7 & 81 & 80 & 1.23 & 142 & 139 & 2.11 & 10.16 & 10.12 & 0.39 & 21.39 & 20.55 & 3.90 \\
BHM-9 & 81 & 80 & 1.23 & 142 & 139 & 2.11 & 10.73 & 10.43 & 2.80 & 22.20 & 20.85 & 6.10 \\
PIONEER & 82 & 80 & 2.44 & 143 & 140 & 2.10 & 10.94 & 10.55 & 3.56 & 22.21 & 20.98 & 5.57 \\
NK-40 & 82 & 80 & 2.44 & 143 & 140 & 2.10 & 10.83 & 10.59 & 2.22 & 22.22 & 21.01 & 5.42 \\
\hline
\end{tabular}

BHM7 = BARI Hybrid Maize-7, BHM9 = BARI Hybrid Maize-9; Obs = observed; Sim = simulated. 


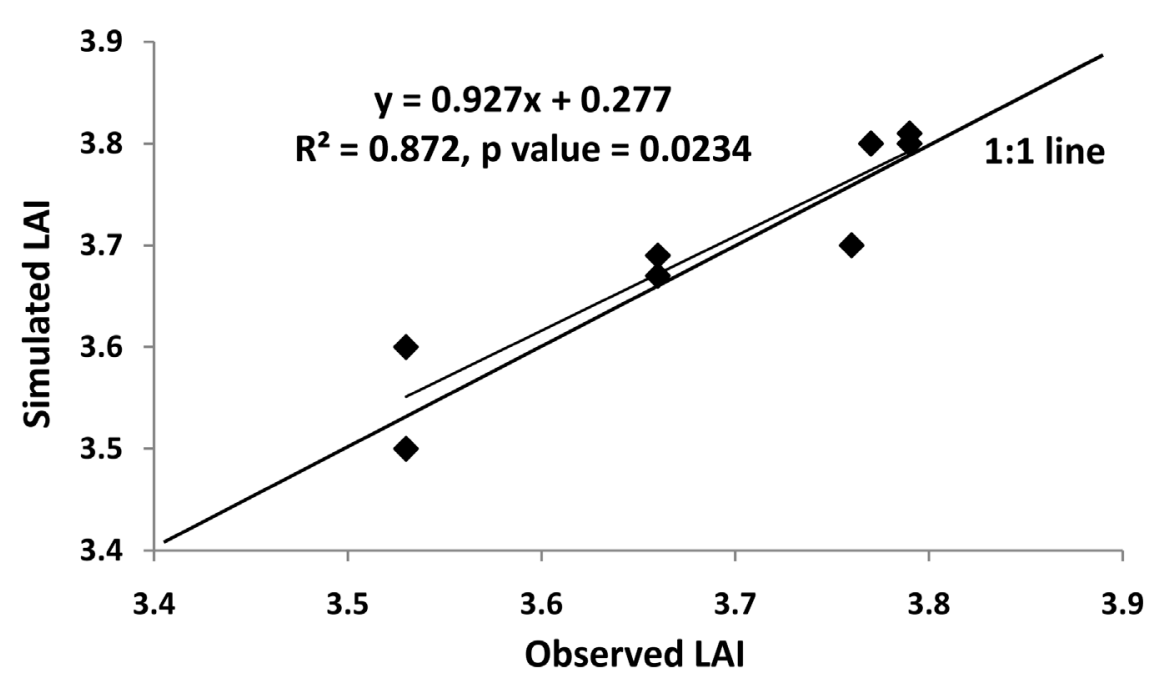

Figure 3. Relationship between simulated and observed maximum leaf area index.

In 2014-15, days to physiological maturity for BARI developed maize varieties were 142 against 139 days of the simulated values. On the other hand, PIONEER and NK-40 took 143 days for physiological maturity against 140 days of the simulated values. The error percentage ranged from 1.45 to 2.11 across the years. There were little variation between observed and simulated grain yields of hybrid maize cultivars over the years, observed grain yield was a little bit higher compared to simulated yield. Similar trend was found in tops weight at.harvest.

Table 5 shows the simulated and observed days to anthesis, days to maturity, grain yield and tops weight at.harvest. During 2015-16 for validation, simulated days to anthesis was over estimated compared to simulated values irrespective of cultivars where error percentages ranged from $3.75 \%$ to $4.94 \%$, but days to maturity was in good agreement between observe and simulated values. Grain yield was over estimated compared to simulated results, with error percentage ranged from $2.13 \%$ to $6.81 \%$. Similar trend was found in tops weight at.harvest with error percentage $2.86 \%$ to $4.43 \%$. The estimation error for anthesis and physiological maturity appear reasonable and in line with results of other studies in which field data were used to estimate genetic coefficients [22] [23] [24] [25].

\subsection{Biomass at Harvest}

Figure 4 shows relationship between simulated and observed biomass at harvest. Observed and simulated biomass matched well where coefficient of determination $\left(\mathrm{R}^{2}\right)$ was around $97 \%$, and thereby could demonstrate satisfactory performance of the model.

\subsection{Grain Yield}

Figure 5 shows the performance of DSSAT model in terms of observed versus simulated grain yield. The regression line was more or less near to 1:1 line, indicating that the model was performing well under the test environment. Similarly, goodness of fit $\left(R^{2}\right)$ as well as regression coefficients between observed and si- 


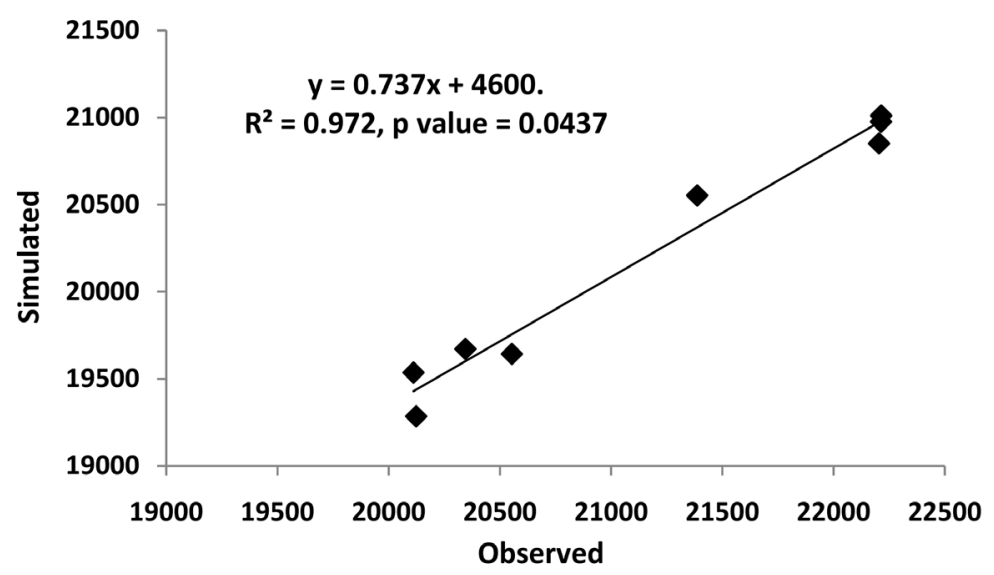

Figure 4. Relationship between simulated and observed biomass $\left(\mathrm{kg} \cdot \mathrm{ha}^{-1}\right)$ at the harvest of maize cultivars.

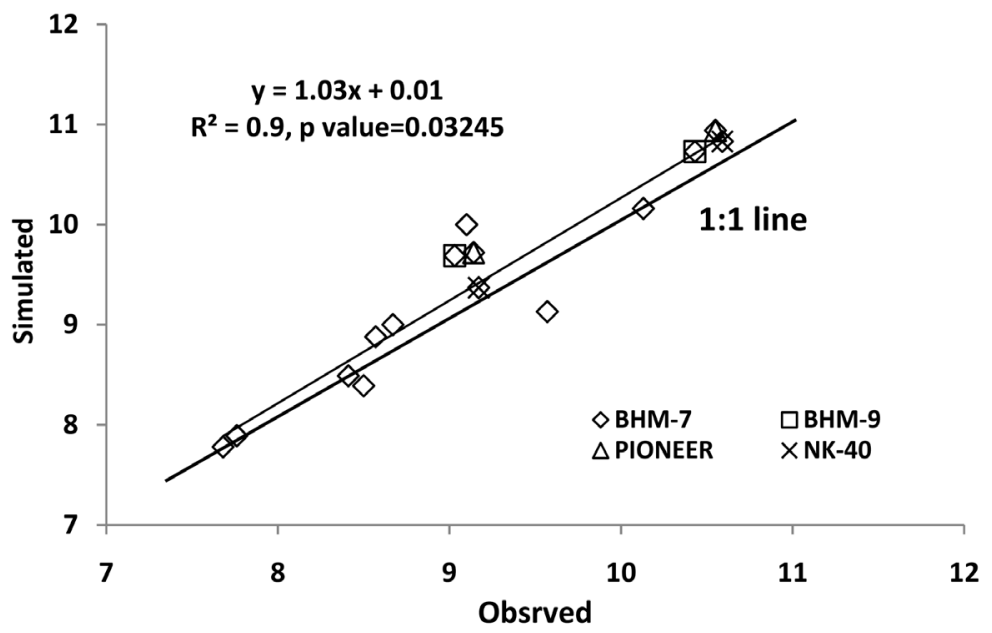

Figure 5. Relationship between simulated and observed yield $\left(\mathrm{t} \cdot \mathrm{ha}^{-1}\right)$ of maize cultivars. (BHM7 = BARI Hybrid Maize-7, BHM9 = BARI Hybrid Maize-9).

Table 5. Simulated and observed values for four maize cultivars for days to anthesis, days to maturity, grain yield and biomass at harvest (2015-2016, process of validation).

\begin{tabular}{ccccccccccccccc}
\hline \multirow{2}{*}{ Cultivar } & \multicolumn{3}{c}{ Days to anthesis } & \multicolumn{3}{c}{ Days to maturity } & \multicolumn{3}{c}{ Grain yield $\left(\mathrm{tha}^{-1}\right)$} & \multicolumn{3}{c}{ Tops weight $\left(\mathrm{tha}^{-1}\right)$} \\
\cline { 2 - 13 } & Obs & Sim. & \%Error & Obs. & Sim. & \%Error & Obs. & Sim. & \%Error & Obs. & Sim. & \%Error \\
\hline BHM-7 & 80 & 77 & 3.75 & 137 & 135 & 1.46 & 9.00 & 8.67 & 3.67 & 20.12 & 19.29 & 4.16 \\
BHM-9 & 80 & 77 & 3.75 & 137 & 135 & 1.46 & 9.69 & 9.03 & 6.81 & 20.11 & 19.54 & 2.86 \\
PIONEER & 81 & 77 & 4.94 & 138 & 136 & 1.45 & 9.70 & 9.14 & 5.97 & 20.55 & 19.64 & 4.43 \\
NK-40 & 81 & 77 & 4.94 & 138 & 136 & 1.45 & 9.37 & 9.17 & 2.13 & 20.35 & 19.67 & 3.31 \\
\hline
\end{tabular}

BHM7 = BARI Hybrid Maize-7, BHM9 = BARI Hybrid Maize-9; Obs = observed; Sim = simulated .

mulated data was significant. The coefficient of prediction was to the extent of $90 \%$ in case of trend run between the observed and simulated values.

CERES-Maize calibration and validation for major cultivars for Bangladesh production environment opens the way for use of the DSSAT model for inputs and resource management, yield forecasting and climate change impact analysis. 
The performance of the model after its calibration was satisfactory and the results were within significant limits and were similar to the results of Jones, and Thornton, 2003 and Ma, et al., 2006. The model, in the present study, was funder non-limiting conditions of water and nitrogen, which is the major production environment of maize crop in Bangladesh.

\section{Conclusion}

Maize has taken an important place among cereal crops of Bangladesh after the introduction of hybrid genotypes. It is necessary to understand the growth behavior of hybrid maize in different production environment, especially to address future climate change impacts. Since crop growth model plays an important role in delineating variability study performances, The DSSAT was calibrated and validated for Gazipur environment using field experimental data. The performance of the model was evaluated through phenology, biomass at harvest, leaf area index and grain yield. The simulated results were in close agreement with the observed values and these were within the statistical significance limit. Biomass, to some extent, was over predicted by the simulation but within significant limit. Simulated and observed phenology and yields were in close agreement with the observed values. It can be inferred that the DSSAT version 4.6 can be successfully employed for simulating the growth and yield of maize hybrids grown under various biotic and abiotic stresses, including evaluation of the climate change impact analysis in Bangladesh.

\section{Acknowledgements}

The authors gratefully acknowledge the financial support provided by Bangladesh Krshi Gobeshona Foundation (KGF) under the project entitled "Modelling Climate Change Impact on Agriculture and Developing Mitigation and Adaptation Strategies for Sustaining Agricultural Production in Bangladesh" executed by BARI, BRRI and BSMARU.

\section{Conflicts of Interest}

The authors declare no conflict of interest.

\section{References}

[1] Rosenzweig, C. and Liverman, D. (1992) Predicted Effects of Climate Change on Agriculture: A Comparison of Temperate and Tropical Regions. In: Majumdar, S.K., Ed., Global Climate Change: Implications, Challenges, and Mitigation Measures, The Pennsylvania Academy of Sciences, PA, 342-361.

[2] White, J.W., Hoogenboom, G., Kimball, B.A. and Wall, G.W. (2011) Methodologies for Simulating Impacts of Climate Change on Crop Production. Field Crops Research, 124, 357-368.

[3] Aggarwal, P.K. and Kalra, N. (1994) Analysing the Limitations Set by Climatic Factors, Genotype, Water and Nitrogen Availability on Productivity of Wheat. II. Climatically Potential Yields and Optimal Management Strategies. Field Crops Research, 38, 93-103. 
[4] Aggarwal, P.K., Banerjee, B., Daryaei, M.G., Bhatia, A., Bala, A., Rani, S., Chander, S., Pathak, H. and Kalra, N. (2006) Infocrop: A Dynamic Simulation Model for the Assessment of Crop Yields, Losses Due to Pests and Environmental Impact of Agro-Ecosystems in Tropical Environments. II. Performance of the Model. Agricultural Systems, 89, 47-67.

[5] Aggarwal, P.K., Kalra, N., Chander, S. and Pathak, H. (2006) Infocrop: A Dynamic Simulation Model for the Assessment of Crop Yields, Losses Due to Pests and Environmental Impact of Agro-Ecosystems in Tropical Environments. II. Model Description. Agricultural Systems, 89, 1-25.

[6] Kalra, N., Chakraborty, D., Sharma, A., Rai, H.K., Jolly, M., Chander, S., Ramesh Kumar, P., Bhadraray, S., Barman, D., Lal, M. and Sehgal, M. (2008) Effect of Increasing Temperature on Yield of Some Winter Crops in North-West India. Current Science, 94, 82-88.

[7] Jones, J.W., Hoogenboom, G., Porter, C.H., Boote, K.J., Batchelor, W.D. and Hunt, L.A., et al. (2003) The DSSAT Cropping System Model. European Journal of Agronomy, 18, 235-265.

[8] Uehara, G. and Tsuji, G.Y. (1998) Overview of IBSNAT. In: Tsuji, G.Y., Hoogemboom, G. and Thornton, P.K., Eds., Understanding Options for Agricultural Production, Kluwer Academic Publishers, Dordrecht, 1-7.

https://doi.org/10.1007/978-94-017-3624-4_1

[9] Jones, P.G. and Thornton, P.K. (2003) The Potential Impacts of Climate Change on Maize Production in Africa and Latin America in 2055. Global Environmental Change, 13, 51-59. https://doi.org/10.1016/S0959-3780(02)00090-0

[10] Hunt, L.A. and Boote, K.J. (1998) Data for Model Operation, Calibration and Evaluation. In: Tsuji, G.Y., Hoogenboom, G. and Thornton, P.K., Eds., Understanding Options for Agricultural Production, Kluwer Academic Publishers/ICASA, Dordrecht, 9-40. https://doi.org/10.1007/978-94-017-3624-4_2

[11] Hoogenboom, G., Jones, J.W., Wilkens, P.W., Porter, C.H., Boote, K.J. and Hunt, L.A. (2010) Decision Support System for Agrotechnology Transfer (DSSAT). Version 4. 5, University of Hawaii, Honolulu, Hawaii.

[12] MacCarthy, D.S., Vlek, P.L.G. and Fosu-Mensah, B.Y. (2012) The Response of Maize to N Fertilization in a Sub-Humid Region of Ghana: Understanding the Process Using a Crop Simulation Model. In: Kihara, J., Fatondji, D., Jones, J.W., Hoogenboom, G., Tabo, R. and Bationo, A., Eds., Improving Soil Fertility Recommendations in Africa using the Decision Support System for Agrotechnology Transfer (DSSAT), Springer Science + Business Media, Dordrecht, 61-75. https://doi.org/10.1007/978-94-007-2960-5_5

[13] Mupangwa, W., Dimes, J., Walker, S. and Twomlow, S. (2011) Measuring and Simulating Maize (Zea mays L.) Yield Responses to Reduced Tillage and Mulching under Semi-Arid Conditions. Agricultural Sciences, 2, 167-174. https://doi.org/10.4236/as.2011.23023

[14] Craufurd, P.Q., Vadez, V., Jagadish, S.V.K., Vara-Prasad, P.V. and Zaman-Allah, M. (2013) Crop Science Experiments Designed to Inform Crop Modeling. Agricultural and Forest Meteorology, 170, 8-18. https://doi.org/10.1016/j.agrformet.2011.09.003

[15] Hunt, L.A. (1993) Designing Improved Plant Types: A Breeder's Viewpoint. In: Penning de Vries, F., Teng, P. and Metselaar, K., Eds., Systems Approaches for Agricultural Development, Kluwer Academic Press, Boston, 3-17.

[16] Sarkar, R. and Kar, S. (2006) Evaluation of Management Strategies for Sustainable Rice-Wheat Cropping System, Using DSSAT Seasonal Analysis. Journal of Agricultural Science, 144, 421-434. https://doi.org/10.1017/S0021859606006447 
[17] Saseendran, S.A., Nielsen, D.C., Ahuja, L.R., Ma, L. and Lyon, D.J. (2013) Simulated Yield and Profitability of Five Potential Crops for Intensifying the Dryland WheatFallow Production System. Agricultural Water Management, 116, 175-192. https://doi.org/10.1016/j.agwat.2012.07.009

[18] Ma, L., Hoogenboom, G., Ahuja, L.R., Ascough Ii, J.C. and Saseendran, S.A. (2006) Evaluation of the RZWQM-CERES-Maize Hybrid Model for Maize Production. Agricultural Systems, 87, 274-295. https://doi.org/10.1016/j.agsy.2005.02.001

[19] Mavromatis, T., Boote, K.J., Jones, J.W., Irmak, A., Shinde, D. and Hoogenboom, G. (2001) Developing Genetic Coefficients for Crop Simulation Models with Data from Crop Performance Trials. Crop Science, 41, 40-51.

https://doi.org/10.2135/cropsci2001.41140x

[20] Cenacchi, N. and Koo, J. (2011) Effects of Drought Tolerance on Maize Yield in Sub-Saharan Africa.

http://addis2011. ifpri. info/files/2011/10/Paper_4C_Nichola-Cenacci. pdf

[21] Lukeba J.L., Nkongolo, J.C.L., Mwabila, K.C.K. and Tsumbu, M.L. (2013) Growth and Leaf Area Index Simulation in Maize (Zea mays L.) under Small-Scale Farm Conditions in a Sub-Saharan African Region. American Journal of Plant Sciences, 4 , 575-583. https://doi.org/10.4236/ajps.2013.43075

[22] Irmak, A., Jones, J.W., Mavromatis, T., Welch, K.J., Boote, S.M. and Wilkerson, G.G. (2000) Evaluating Methods for Simulating Soybean Cultivar Responses Using cross Validation. Agronomy Journal, 92, 1140-1149. https://doi.org/10.2134/agronj2000.9261140x

[23] Roman-Paoli, E., Welch, S.M. and Vanderlip, R.L. (2000) Comparing Genetic Coefficient Estimation Methods Using the CERES-Maize Model. Agricultural Systems, 65, 29-41. https://doi.org/10.1016/S0308-521X(00)00024-X

[24] Mavromatis, T.K., Boote, J., Jones, J.W., Wilkerson, G.G. and Hoogenboom, G. (2002) Repeatability of Model Genetic Coefficients Derived from Soybean Performance Trials cross Different States. Crop Science, 42, 76-89. https://doi.org/10.2135/cropsci2002.0076

[25] Gungula, D.T., Kling, J.G. and Togun, A.O. (2003) CERES-Maize Predictions of Maize Phenology under Nitrogen-Stressed Condition in Nigeria. Agronomy Journal, 95, 892-899. https://doi.org/10.2134/agronj2003.0892

\section{Scientific Research Publishing}

Submit or recommend next manuscript to SCIRP and we will provide best service for you:

Accepting pre-submission inquiries through Email, Facebook, LinkedIn, Twitter, etc. A wide selection of journals (inclusive of 9 subjects, more than 200 journals)

Providing 24-hour high-quality service

User-friendly online submission system

Fair and swift peer-review system

Efficient typesetting and proofreading procedure

Display of the result of downloads and visits, as well as the number of cited articles

Maximum dissemination of your research work

Submit your manuscript at: http://papersubmission.scirp.org/

Or contact ajps@scirp.org 